Research Article

\title{
Rapid Screening and Quantitative Determination of Active Components in Qing-Hua-Yu-Re-Formula Using UHPLC-Q-TOF/MS and HPLC-UV
}

\author{
Xin Shao, ${ }^{1,2}$ Jie Zhao, ${ }^{3}$ Xu Wang ${ }^{(D)},{ }^{1}$ and Yi Tao ${ }^{4}$ \\ ${ }^{1}$ The First Clinical Medical College, Nanjing University of Chinese Medicine, Nanjing 210023, China \\ ${ }^{2}$ Department of Endocrinology, Nanjing Hospital of Traditional Chinese Medicine, Nanjing 210001, China \\ ${ }^{3}$ Pharmaceutical Animal Experimental Center, China Pharmaceutical University, Nanjing 210009, China \\ ${ }^{4}$ School of Pharmacy, Nanjing University of Chinese Medicine, Nanjing 210023, China
}

Correspondence should be addressed to Xu Wang; wangxunjzy@163.com

Received 23 October 2017; Accepted 24 January 2018; Published 11 March 2018

Academic Editor: Eduardo Dellacassa

Copyright ( $) 2018$ Xin Shao et al. This is an open access article distributed under the Creative Commons Attribution License, which permits unrestricted use, distribution, and reproduction in any medium, provided the original work is properly cited.

\begin{abstract}
Qing-Hua-Yu-Re-Formula (QHYRF), a new herbal preparation, has been extensively used for treating diabetic cardiomyopathy. However, the chemical constituents of QHYRF remain uninvestigated. In the present study, rapid ultrahigh-performance liquid chromatography coupled with quadrupole-time-of-flight mass spectrometry (UHPLC-Q-TOF/MS) was used to qualitatively analyze the components of QHYRF. Qualitative detection was performed on a Kromasil $\mathrm{C}_{18}$ column through the gradient elution mode, using acetonitrile-water containing $0.1 \%$ formic acid. Twenty-seven compounds were identified or tentatively characterized, including 12 phenolic acids, nine monoterpene glycosides, two flavonoids, three iridoids, and one unknown compound. Among these, six compounds were confirmed by comparing with standards. A high-performance liquid chromatography (HPLC) method was developed to simultaneously determine the following six active components in QHYRF: danshensu, paeoniflorin, acteoside, lithospermic acid, salvianolic acid B, and salvianolic acid C. These HPLC chromatograms were monitored at 254, 280, and $320 \mathrm{~nm}$. The method was well validated with respect to specificity, linearity, limit of detection, limit of quantification, precision, stability, and recovery. The HPLC-UV method was successfully applied to 10 batches of QHYRF.
\end{abstract}

\section{Introduction}

An increasing number of people have suffered from diabetes in recent years, and cardiovascular complications secondary to diabetes have become the main cause of death in diabetic patients. The incidence of cardiovascular disease in patients with diabetes is 2-3 times higher than that of nondiabetic patients [1]. Diabetic cardiomyopathy (DCM), a specific cardiomyopathy and one of the major cardiac complications in diabetic patients, was found in diabetic patients without significant coronary artery atherosclerosis by Rubler et al. in 1972 [2]. Few clinical symptoms were observed in early DCM. However, with the further development of the disease, patients have become more susceptible to heart failure due to myocardial microvascular and metabolic disorders, which lead to changes in myocardial cell dysfunction and structure.
Moreover, DCM is closely related to the high incidence of cardiovascular disease and high mortality in patients with diabetes. It was reported that the prevalence of DCM in patients with type 2 diabetes is approximately $12 \%$ [3].

At present, controlling blood sugar and improving heart failure are the main ways to overcome DCM. However, treatment with Western medicine remains unsatisfactory. Therefore, the diagnosis and therapy for DCM have presently become pressing problems. Traditional Chinese herbal formulation (TCMF) has been widely used in clinic due to its well-proven efficacy and few side effects. The Qing-Hua-YuRe-Formula (QHYRF) is a new herbal preparation for treating DCM, which was developed by Professor Wang Xu, according to the clinic experience of Chinese Medicine Master Professor Zhou Zhongying. The recipe of QHYRF comprises six herbal medicines: radix rehmanniae recen, 
Salvia miltiorrhiza Bge, cortex moutan, Rhizoma coptidis, radix paeoniae rubra, and Euonymus alatus. Emerging evidences have indicated that the six major active components (danshensu, paeoniflorin, acteoside, lithospermic acid, salvianolic acid B, and salvianolic acid C) in QHYRF protect cardiomyocytes by antioxidation, anti-inflammation, antiapoptosis, and decreasing calcium overload [4-7]. Moreover, clinical studies have shown that QHYRF could effectively improve symptoms in patients with DCM, including blood sugar, blood rheology, and left ventricular structure and function. According to the known effective components, we speculate that the effect of myocardial protection of QHYRF could be achieved through the following methods: (1) increase myocardial glucose transporter gene expression to improve glucose and lipid metabolism; (2) decrease the level of inflammatory cytokine hypersensitive C-reactive protein and tumor necrosis factor-alpha, and increase serum adiponectin levels to reduce inflammation; (3) reduce glucose toxicity; (4) increase insulin sensitivity and improve insulin resistance; (5) reduce the apoptosis of cardiac muscle cells and decrease the PAI-1 level of the fibrinolysis system; (6) improve blood stasis $[8,9]$.

It has been widely accepted that the chemical composition of traditional Chinese medicine (TCM) is complex, and its improper use may cause toxic effects [10]. Therefore, the quality control of TCM is extremely important. However, few researches have been carried on the chemical composition of QHYRF. Furthermore, the specific content of its main ingredients remains unknown. It should be noted that the constituents and contents of the main active components of QHYRF may be influenced by harvest time, plant origin, and manufacturing procedures $[10,11]$. Thus, there is an urgent need to develop an effective method for QHYRF quality control, in order to guarantee its pharmacological efficacy.

In the present study, both qualitative and quantitative approaches were developed for the comprehensive quality control of QHYRF. Twenty-seven compounds were identified or tentatively characterized by ultrahigh-performance liquid chromatography coupled with quadrupole-time-offlight mass spectrometry (UHPLC-Q-TOF/MS), including 12 phenolic acids, nine monoterpene glycosides, two flavonoids, three iridoids, and one unknown compound. Moreover, a simple, reliable, and sensitive analytical method, the high-performance liquid chromatography with ultraviolet detection (HPLC-UV) method, was used to determine the quantity of the six major active components (danshensu, paeoniflorin, acteoside, lithospermic acid, salvianolic acid B, and salvianolic acid C) of QHYRF. The potential application of the present study not only supports the quality control of QHYRF but also provides a theoretical research basis for the further research of QHYRF in clinic.

\section{Experimental}

2.1. Chemicals and Materials. Six crude herbs (cortex mouta, Rhizoma coptidis, Euonymus alatus, Rehmannia glutinosa, Salvia miltiorrhiza, and Paeonia lactiflora) were obtained from the pharmacy in Nanjing Hospital of Traditional
Chinese Medicine, according to the Chinese Pharmacopoeia (2010 edition). The standard compounds (purity $>98 \%$; danshensu, paeoniflorin, acteoside, lithospermic acid, salvianolic acid $\mathrm{B}$, and salvianolic acid $\mathrm{C}$ ) were purchased from Sichuan Victor Biotechnology Co., Ltd. HPLC-grade acetonitrile was obtained from Merck Co. All solutions and dilutions were prepared with ultrapure water obtained from a Milli-Q water purification system.

The extraction procedures for QHYRF total fraction were as follows: first, $15 \mathrm{~g}$ of radix rehmanniae recen, $15 \mathrm{~g}$ of Salvia miltiorrhiza Bge, $10 \mathrm{~g}$ of paeonol, $5 \mathrm{~g}$ of Rhizoma coptidis, $10 \mathrm{~g}$ of radix paeoniae rubra, and $10 \mathrm{~g}$ of Euonymus alatus were extracted twice with water $(\times 8)$ to yield a crude extract. Second, the crude extract was concentrated and spray-dried to obtain the final product.

2.2. Sample Preparation. The samples were prepared as follows: $20 \mathrm{mg}$ of QHYRF total fraction was dissolved in $1 \mathrm{~mL}$ of methanol and ultrasonicated for 15 minutes. Then, the sample solution was centrifuged at 12,000 rpm for 10 minutes, transferred to vials, and subjected to UHPLC-Q-TOF/MS and HPLC-UV analysis.

2.3. UHPLC-Q-TOF/MS Analysis. The analytical included a Shimadzu UHPLC system and a Q-TOF 5600-plus mass spectrometer equipped with Turbo $\mathrm{V}$ source and a TurboIonSpray interface (AB Sciex) and an Agilent 1100 LC-UV system with ChemStation (Agilent). The chromatographic conditions were as follows [12]: Kromasil $\mathrm{C}_{18}$ column $(4.6 \times 150 \mathrm{~mm}, 5 \mu \mathrm{m})$ at $35^{\circ} \mathrm{C}$, sample injection volume, $10 \mu \mathrm{L}$; mobile phases, water containing $0.1 \%$ formic acid (solvent A) and acetonitrile (solvent B); gradient program was employed according to the following programmer: $0-5$ minutes, $5-15 \% \mathrm{~B}$; $5-10$ minutes, linear increase to $20 \% \mathrm{~B}$; $10-20$ minutes, linear increase to $25 \% \mathrm{~B} ; 20-30$ minutes, linear increase to $100 \% \mathrm{~B} ; 30-35$ minutes, hold on $100 \% \mathrm{~B}$.

The operating parameters for Q-TOF/MS were set as follows [12]: ion spray voltage, $-4.5 \mathrm{kV}$; collision energy, $-35 \mathrm{eV}$; nebulizer gas (gas 1), $55 \mathrm{psi}$; declustering potential, $-60 \mathrm{~V}$; heater gas (gas 2), $55 \mathrm{psi}$; turbo spray temperature, $550^{\circ} \mathrm{C}$; curtain gas, 35 psi; resolution, 20,000. Full-scan data acquisition was performed from $\mathrm{m} / \mathrm{z} 100$ to 1500 in the negative mode.

2.4. HPLC-UV Analysis. The analysis was performed on a Shimadzu HPLC system. Chromatographic separation was achieved on an XBridge $C_{18}$ column $(4.6 \times 150 \mathrm{~mm}, 5 \mu \mathrm{m})$. The temperature of the column oven was set at $30^{\circ} \mathrm{C}$, and the flow rate was $1.0 \mathrm{~mL} / \mathrm{min}$. The sample injection volume was $10 \mu \mathrm{L}$. The mobile phases were a mixture of water with $0.1 \%$ formic acid (solvent A) and acetonitrile (solvent B). A gradient program was employed according to the following profile: $0-10$ minutes, $10-15 \% \mathrm{~B} ; 10-25$ minutes, linear increase to $30 \% \mathrm{~B} ; 25-60$ minutes, linear increase to $100 \% \mathrm{~B}$. The UV wavelength was set at $254 \mathrm{~nm}$ (paeoniflorin, lithospermic acid, and salvianolic acid B), $280 \mathrm{~nm}$ (danshensu and salvianolic acid C), and $320 \mathrm{~nm}$ (acteoside). 


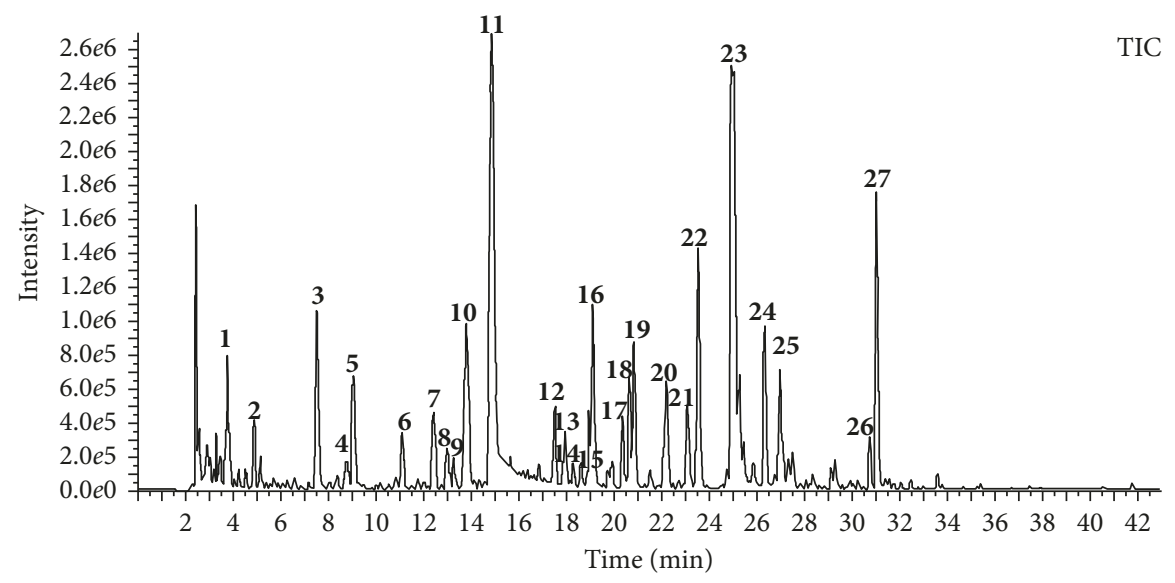

Figure 1: TIC chromatogram of QHYRF using UHPLC-Q-TOF/MS.

2.5. Validation of the Established HPLC-UV Approach. The stock solution that contained the six reference compounds $(0.5 \mathrm{mg} / \mathrm{mL}$ danshensu, $25 \mathrm{mg} / \mathrm{mL}$ paeoniflorin, $1 \mathrm{mg} / \mathrm{mL}$ acteoside, $1 \mathrm{mg} / \mathrm{mL}$ lithospermic acid, $10 \mathrm{mg} / \mathrm{mL}$ salvianolic acid $B$, and $1 \mathrm{mg} / \mathrm{mL}$ salvianolic acid C) was prepared in methanol and stored at $4^{\circ} \mathrm{C}$. In order to establish the calibration curves, the stock solution was diluted to appropriate concentrations. Solutions that contained different concentrations of the six standard compounds were injected in triplicate. The calibration curves were peak areas versus the concentration for each compound [12].

The limit of detection (LOD) was determined as a signalto-noise ratio equal to 3 , and the limit of quantification (LOQ) was based on 10 times of the signal-to-noise ratio value.

The precision was evaluated by intraday and interday variability. Intraday reproducibility was carried out by analyzing the individual sample solution six times within one day. For interday variability, six samples were determined six times in three consecutive days.

A stability study was performed with a sample solution checked at $0,4,8,12$, and 24 hours. Variations were expressed by relative standard deviations (RSDs).

Recovery studies were carried out by spiking known amounts of the reference compounds at low, medium, and high concentration in the samples. Then, the spiked samples were thoroughly mixed, extracted, and analyzed in accordance with the methods mentioned above. Recovery $(\%)=($ amount found - original amount)/amount spiked $\times 100 \%$ [12].

2.6. Application to Different Batches of QHYRF. The established HPLC-UV method was subsequently employed for the simultaneous quantification of danshensu, paeoniflorin, acteoside, lithospermic acid, salvianolic acid B, and salvianolic acid $\mathrm{C}$ in QHYRF from 10 different batches.

\section{Results and Discussion}

3.1. UHPLC-Q-TOF-MS Analysis. The UHPLC-Q-TOF/MS approach was employed for the separation and identification of compounds in QHYRF. The total ion current chromatogram is shown in Figure 1. A total of 27 compounds were identified, including 12 phenolic acids, nine monoterpene glycosides, two flavonoids, three iridoids, and one unknown compound. The detailed information is displayed in Table 1. The retention time and fragmentation information of compounds $2,11,16,22,23$, and 26 were compared with that of the standard compounds.

Phenolic acids were the major components of QHYRF. A total of 12 phenolic acids were identified and tentatively characterized based on their mass data and reports in literature. These always exhibited a unique fragmentation behavior. The characteristic mass behaviors of these phenolic compounds were the losses of danshensu (198 Da) and caffeic acid (180 Da) molecules. Peak 2 revealed the $[\mathrm{M}-\mathrm{H}]^{-}$ ion at $m / z 197.0467$ and gave the element composition of $\mathrm{C}_{9} \mathrm{H}_{10} \mathrm{O}_{5}$. In the $\mathrm{MS}^{2}$ spectra, the ions at $m / z 135$ and 179 were observed, which was consistent with that of danshensu. In comparison with the reference, compound $\mathbf{2}$ was unambiguously identified as danshensu (Figure 2(a)). Peaks 20, 23, and 24 displayed the same $[\mathrm{M}-\mathrm{H}]^{-}$ion at $\mathrm{m} / z 717.1472$ $\left(\mathrm{C}_{36} \mathrm{H}_{30} \mathrm{O}_{16}\right)$. In comparison with standard compound, compound 23 was unambiguously assigned as salvianolic acid B (Figure 2(e)). The product ion at $m / z 339$ was formed due to the disconnection of another caffeic acid $(180 \mathrm{Da})$ molecule from the deprotonated daughter ion [M-H-198] at $m / z 519$. Further loss of $\mathrm{H}_{2} \mathrm{O}$ led to the yield of product ion at $m / z$ 321. Peaks 20 and $\mathbf{2 4}$ shared the same MS ${ }^{2}$ ions with that of compound 23. Compared with literatures [13, 14], compounds 20 and 24 was plausibly deduced as salvianolic acid E and isosalvianolic acid B. Peaks 14, 18, and 22 were a group of isomeric compounds, and these displayed $[\mathrm{M}-\mathrm{H}]^{-}$ ions at $m / z 537.1041\left(\mathrm{C}_{27} \mathrm{H}_{22} \mathrm{O}_{12}\right)$. These had similar fragmentation pathways to those of salvianolic acid $\mathrm{A}$ and generated similar fragment ions at $\mathrm{m} / z$ 313, 295, and 185 . Peak 22 was unequivocally identified as lithospermic acid by comparison with the standard (Figure 2(d)). According to the literature [14], peaks $\mathbf{1 8}$ and $\mathbf{1 4}$ were tentatively identified as salvianolic acid $\mathrm{H}$ or salvianolic acid A. Peak 19 revealed the $[\mathrm{M}-\mathrm{H}]^{-}$ion at $m / z \quad 417.0826$ and gave the element composition of $\mathrm{C}_{20} \mathrm{H}_{18} \mathrm{O}_{10}$. This generated a series of fragment ions at $m / z 373,197,179$, and 175. Compared with the 
TABLE 1: $\mathrm{MS}^{1}$ and $M S^{2}$ information of the QHYRF.

\begin{tabular}{|c|c|c|c|c|c|c|c|}
\hline Number & $\begin{array}{c}t_{R} \\
(\mathrm{~min})\end{array}$ & $\mathrm{MS}^{1}$ & $\mathrm{MS}^{2}$ & Formula & Error & Identification & Source \\
\hline 1 & 3.7 & 719.2063 & 359.0976, 197.0432, 179.0326 & $\mathrm{C}_{48} \mathrm{H}_{32} \mathrm{O}_{7}$ & -1.7 & - & - \\
\hline $2^{*}$ & 4.9 & 197.0467 & $179.0340, \mathbf{1 3 5 . 0 4 4 8}, 123.0452,72.9960$ & $\mathrm{C}_{9} \mathrm{H}_{10} \mathrm{O}_{5}$ & 5.9 & Danshensu & $\begin{array}{l}\text { Salvia } \\
\text { miltiorrhiza }\end{array}$ \\
\hline 3 & 7.5 & 495.1498 & $465.1405,345.1118,137.0228$ & $\mathrm{C}_{23} \mathrm{H}_{28} \mathrm{O}_{12}$ & -2.0 & Oxypaeoniflorin & $\begin{array}{l}\text { Paeonia } \\
\text { lactiflora }\end{array}$ \\
\hline 4 & 8.7 & 525.1612 & $495.1546, \mathbf{1 6 7 . 0 3 3 8}$ & $\mathrm{C}_{24} \mathrm{H}_{30} \mathrm{O}_{13}$ & -0.3 & Mudanpioside E & $\begin{array}{l}\text { Salvia } \\
\text { miltiorrhiza }\end{array}$ \\
\hline 5 & 9.0 & 367.1033 & $193.0490,134.0362$ & $\mathrm{C}_{17} \mathrm{H}_{20} \mathrm{O}_{9}$ & -0.4 & 5-O-Feruloylquinic acid & $\begin{array}{c}\text { Salvia } \\
\text { miltiorrhiza }\end{array}$ \\
\hline 6 & 11.1 & 505.1562 & $459.1522,293.0870, \mathbf{1 6 5 . 0 5 4 3}, 150.0308$ & $\mathrm{C}_{20} \mathrm{H}_{28} \mathrm{O}_{12}$ & 3.0 & Paeonolide & $\begin{array}{l}\text { Paeonia } \\
\text { lactiflora }\end{array}$ \\
\hline 7 & 12.4 & 505.1563 & $\begin{array}{c}459.1526,293.0873,233.0656, \mathbf{1 6 5 . 0 5 4 7} \\
150.0310\end{array}$ & $\mathrm{C}_{20} \mathrm{H}_{28} \mathrm{O}_{12}$ & 0.0 & Apiopaeonoside & $\begin{array}{l}\text { Salvia } \\
\text { miltiorrhiza }\end{array}$ \\
\hline 8 & 13.0 & 647.1615 & $\begin{array}{c}629.1577,509.1336,491.1226,399.0946 \\
313.0565,271.0453\end{array}$ & $\mathrm{C}_{30} \mathrm{H}_{32} \mathrm{O}_{16}$ & -0.4 & $\begin{array}{l}\text { 6-O-Galloyloxypaeoni- } \\
\text { florin }\end{array}$ & $\begin{array}{l}\text { Paeonia } \\
\text { lactiflora }\end{array}$ \\
\hline 9 & 13.3 & 785.252 & 623.2223, 477.1619, 179.0345, 161.0227 & $\mathrm{C}_{35} \mathrm{H}_{46} \mathrm{O}_{20}$ & 1.3 & Echinacoside & $\begin{array}{l}\text { Rehmannia } \\
\text { glutinosa }\end{array}$ \\
\hline 10 & 13.8 & 367.1036 & $193.0487,191.0543, \mathbf{1 7 3 . 0 4 3 9}, 134.0362$ & $\mathrm{C}_{17} \mathrm{H}_{20} \mathrm{O}_{9}$ & 0.4 & 3-O-Feruloylquinic acid & $\begin{array}{l}\text { Salvia } \\
\text { miltiorrhiza }\end{array}$ \\
\hline $11^{*}$ & 14.8 & 525.1608 & $\begin{array}{c}\text { 479.1554, 449.1453, } 327.1069,165.0539 \\
\mathbf{1 2 1 . 0 2 8 8}\end{array}$ & $\mathrm{C}_{24} \mathrm{H}_{30} \mathrm{O}_{13}$ & -1.1 & Paeoniflorin & $\begin{array}{l}\text { Paeonia } \\
\text { lactiflora }\end{array}$ \\
\hline 12 & 17.5 & 611.1621 & 445.0995, 343.0670, 169.0124 & $\mathrm{C}_{27} \mathrm{H}_{32} \mathrm{O}_{16}$ & 0.6 & Hydroxysafflor yellow A & - \\
\hline 13 & 17.9 & 611.1621 & 445.0998, 169.0131 & $\mathrm{C}_{27} \mathrm{H}_{32} \mathrm{O}_{16}$ & 0.6 & $\begin{array}{l}\text { Hydroxysafflor yellow A } \\
\text { isomer }\end{array}$ & - \\
\hline 14 & 18.3 & 537.1041 & $493.1154,313.0515,295.0600,185.0230$ & $\mathrm{C}_{27} \mathrm{H}_{22} \mathrm{O}_{12}$ & 0.5 & Salvianolic acid A & $\begin{array}{l}\text { Salvia } \\
\text { miltiorrhiza }\end{array}$ \\
\hline 15 & 18.6 & 525.16 & $\begin{array}{c}479.1589,449.1472,317.1086,283.0818 \\
\mathbf{1 2 1 . 0 2 9 3}\end{array}$ & $\mathrm{C}_{24} \mathrm{H}_{30} \mathrm{O}_{13}$ & -0.1 & Paeoniflorin isomer & $\begin{array}{l}\text { Paeonia } \\
\text { lactiflora }\end{array}$ \\
\hline $16^{*}$ & 18.9 & 623.1979 & $461.1680, \mathbf{1 6 1 . 0 2 3 7}$ & $\mathrm{C}_{29} \mathrm{H}_{36} \mathrm{O}_{15}$ & -0.4 & Acteoside & $\begin{array}{l}\text { Rehmannia } \\
\text { glutinosa }\end{array}$ \\
\hline 17 & 20.3 & 623.1983 & $461.1683, \mathbf{1 6 1 . 0 2 3 4}$ & $\mathrm{C}_{29} \mathrm{H}_{36} \mathrm{O}_{15}$ & 0.2 & Forsythoside A & $\begin{array}{l}\text { Rehmannia } \\
\text { glutinosa }\end{array}$ \\
\hline 18 & 20.6 & 537.1034 & $493.1155,313.0502, \mathbf{2 9 5 . 0 5 9 4}, 185.0226$ & $\mathrm{C}_{27} \mathrm{H}_{22} \mathrm{O}_{12}$ & -0.8 & Salvianolic acid $\mathrm{H}$ & $\begin{array}{l}\text { Salvia } \\
\text { miltiorrhiza }\end{array}$ \\
\hline 19 & 20.8 & 417.0826 & $\begin{array}{c}373.0918,197.0432,179.0328, \mathbf{1 7 5 . 0 3 7 9} \\
152.0279\end{array}$ & $\mathrm{C}_{20} \mathrm{H}_{18} \mathrm{O}_{10}$ & -0.3 & Salvianolic acid D & $\begin{array}{l}\text { Salvia } \\
\text { miltiorrhiza }\end{array}$ \\
\hline 20 & 22.2 & 717.1472 & 519.0950, 339.0500, 321.0395, 295.0597 & $\mathrm{C}_{36} \mathrm{H}_{30} \mathrm{O}_{16}$ & 1.5 & Salvianolic acid E & $\begin{array}{l}\text { Salvia } \\
\text { miltiorrhiza }\end{array}$ \\
\hline 21 & 23.1 & 359.0775 & $197.0442,179.0334, \mathbf{1 6 1 . 0 2 3 3}, 133.0287$ & $\mathrm{C}_{18} \mathrm{H}_{16} \mathrm{O}_{8}$ & 0.7 & Rosmarinic acid & $\begin{array}{l}\text { Salvia } \\
\text { miltiorrhiza }\end{array}$ \\
\hline $22^{*}$ & 23.5 & 537.1037 & $493.1172,313.0509, \mathbf{2 9 5 . 0 6 0 8 ,} 185.0236$ & $\mathrm{C}_{27} \mathrm{H}_{22} \mathrm{O}_{12}$ & -0.3 & Lithospermic acid & $\begin{array}{l}\text { Salvia } \\
\text { miltiorrhiza }\end{array}$ \\
\hline $23^{*}$ & 24.9 & 717.1456 & $\begin{array}{c}519.0939,339.0489,321.0386,295.0590 \\
279.0277\end{array}$ & $\mathrm{C}_{36} \mathrm{H}_{30} \mathrm{O}_{16}$ & -0.7 & Salvianolic acid B & $\begin{array}{l}\text { Salvia } \\
\text { miltiorrhiza }\end{array}$ \\
\hline 24 & 26.3 & 717.1468 & $\begin{array}{c}519.0936,339.0487, \mathbf{3 2 1 . 0 3 8 5}, 295.0588 \\
279.0275\end{array}$ & $\mathrm{C}_{36} \mathrm{H}_{30} \mathrm{O}_{16}$ & 1.0 & Isosalvianolic acid B & $\begin{array}{l}\text { Salvia } \\
\text { miltiorrhiza }\end{array}$ \\
\hline 25 & 27.0 & 599.1769 & $569.1709,477.1430, \mathbf{1 3 7 . 0 2 3 4}$ & $\mathrm{C}_{30} \mathrm{H}_{32} \mathrm{O}_{13}$ & -0.2 & Benzoyloxypaeoniflorin & $\begin{array}{l}\text { Paeonia } \\
\text { lactiflora }\end{array}$ \\
\hline $26^{*}$ & 30.7 & 491.0983 & $\begin{array}{c}311.0556,293.0440,265.0492,197.0440 \\
135.0442\end{array}$ & $\mathrm{C}_{26} \mathrm{H}_{20} \mathrm{O}_{10}$ & -0.1 & Salvianolic acid C & $\begin{array}{l}\text { Salvia } \\
\text { miltiorrhiza }\end{array}$ \\
\hline 27 & 31.0 & 629.1872 & $\begin{array}{c}\text { 583.1838, 553.1730, 431.1342, 165.0541, } \\
\mathbf{1 2 1 . 0 2 8 7}\end{array}$ & $\mathrm{C}_{30} \mathrm{H}_{32} \mathrm{O}_{12}$ & -0.6 & Benzoylpaeoniflorin & $\begin{array}{l}\text { Paeonia } \\
\text { lactiflora }\end{array}$ \\
\hline
\end{tabular}

*Indicated compared with standards. The bold numbers represent the most abundant ions.

literature [15], compound 19 was tentatively deduced as salvianolic acid D. Peak 21 displayed the $[\mathrm{M}-\mathrm{H}]^{-}$ion at $\mathrm{m} / \mathrm{z}$ 359.0775 and produced fragment ions at $m / z 197,179$, and 161. In comparison with the reference [15], compound 21 was plausibly assigned as rosmarinic acid. Peak 26 gave an
[M-H] $]^{-}$ion at $m / z 491.0983$ with the molecular composition $\mathrm{C}_{26} \mathrm{H}_{20} \mathrm{O}_{10}$. Compared with the standard, peak 26 was unequivocally identified as salvianolic acid C (Figure 2(f)). Peaks 5 and $\mathbf{1 0}$ displayed the same $[\mathrm{M}-\mathrm{H}]^{-}$ion at $\mathrm{m} / z$ 367.1033 with the molecular composition $\mathrm{C}_{17} \mathrm{H}_{20} \mathrm{O}_{9}$. These 


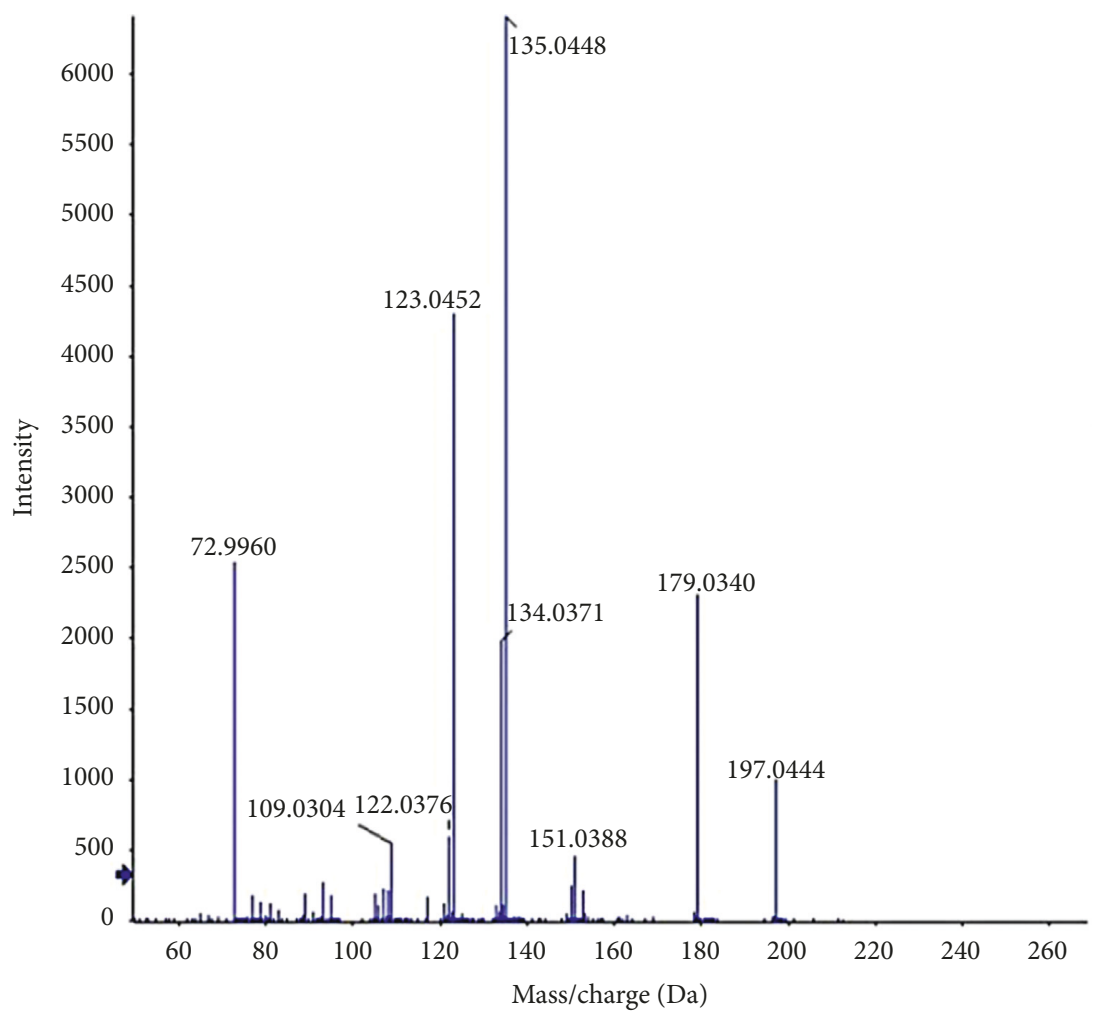

(a)

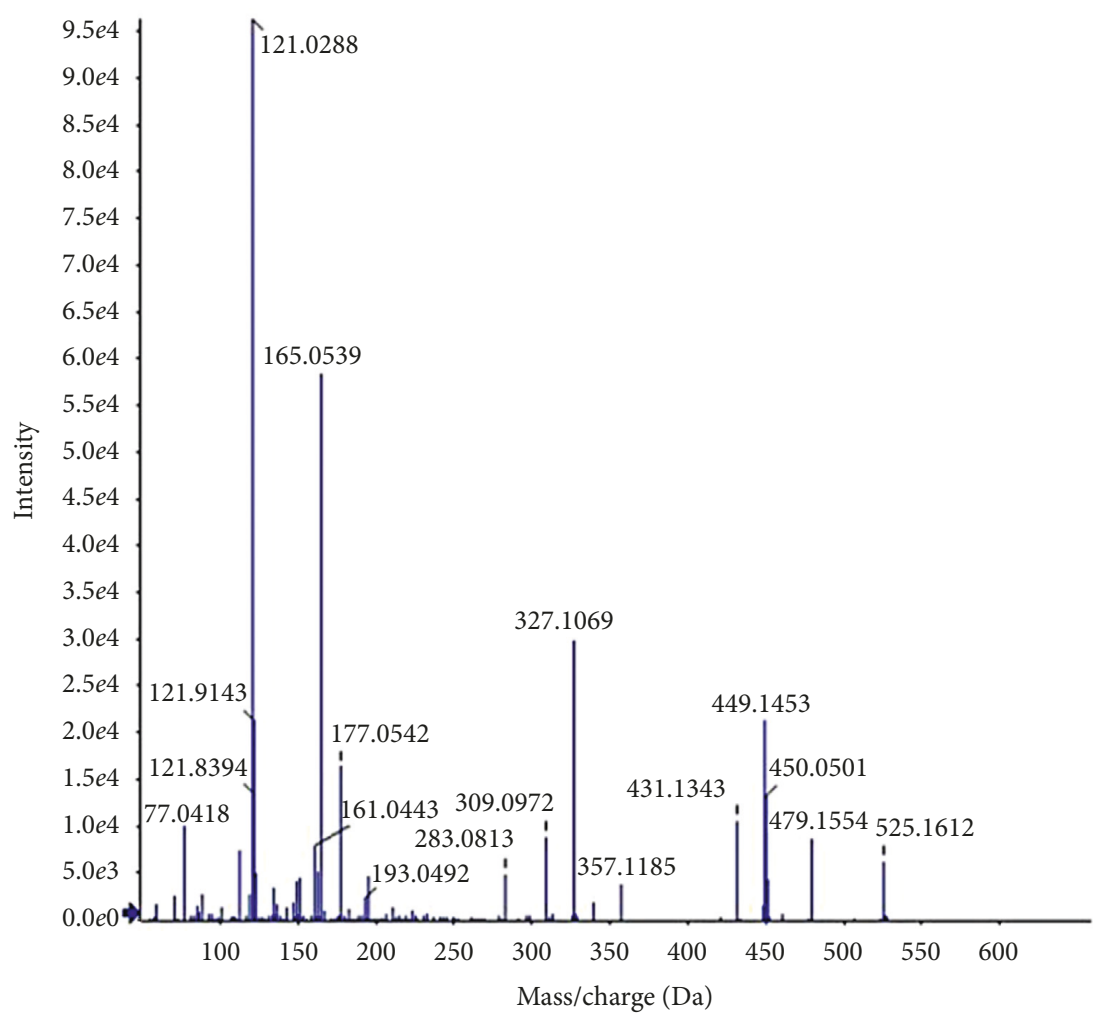

(b)

FIgURe 2: Continued. 


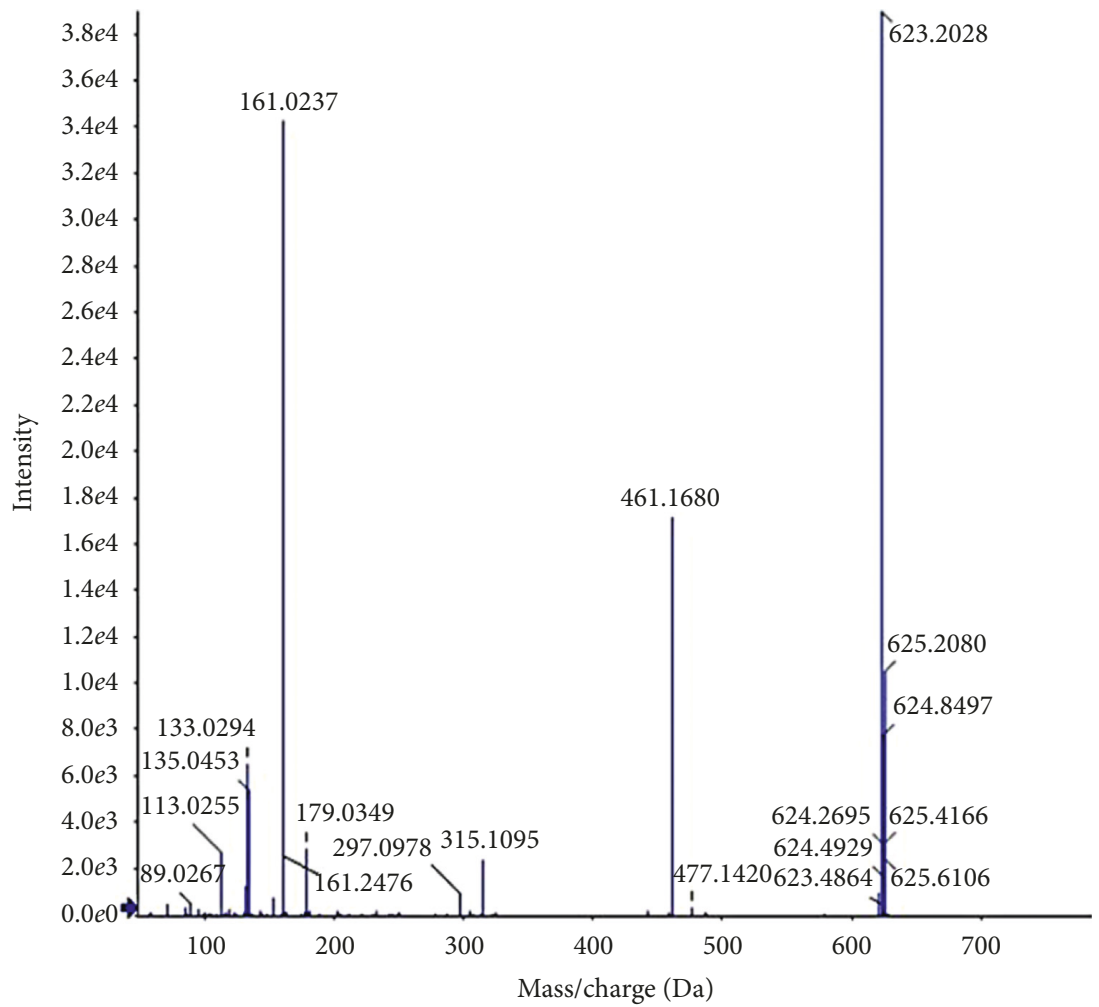

(c)

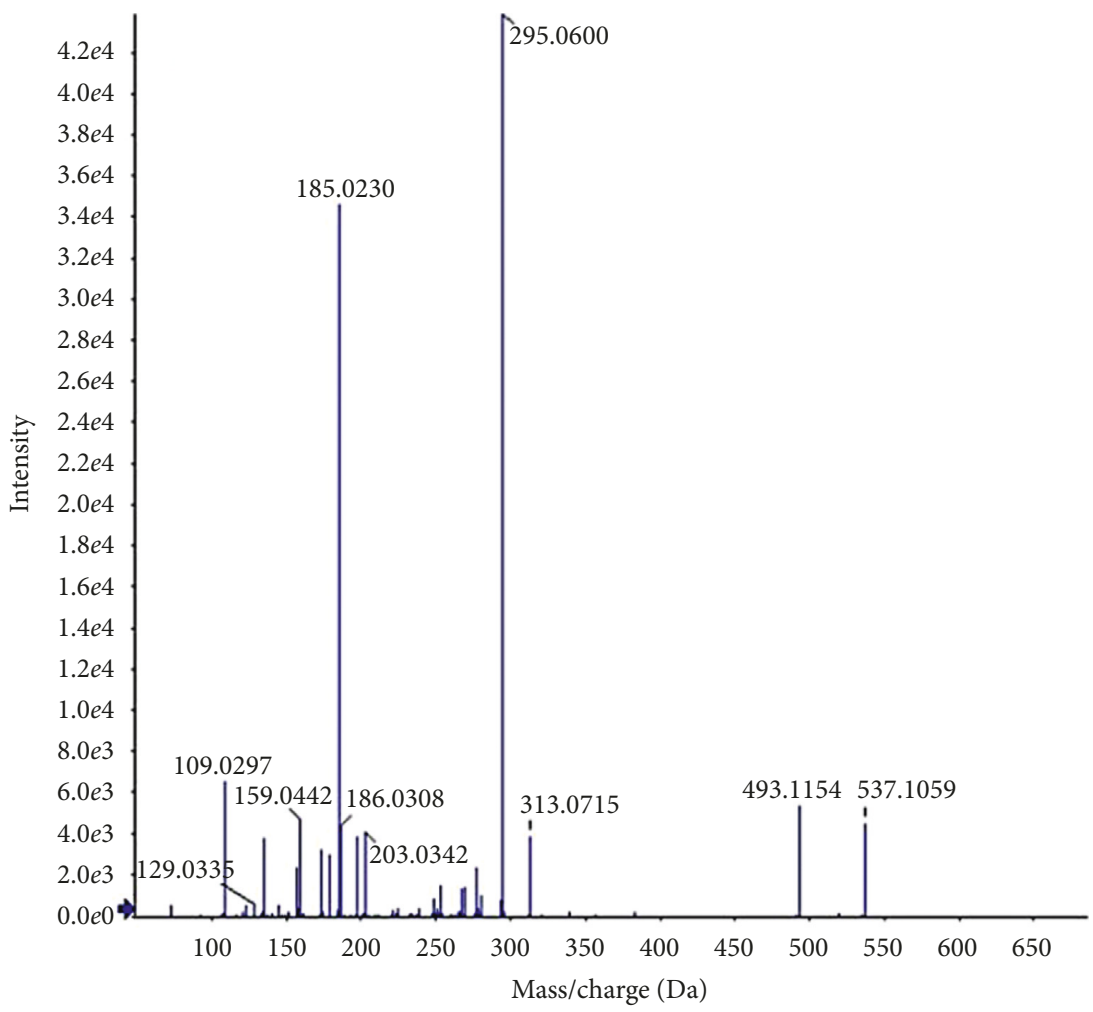

(d)

FIgure 2: Continued. 


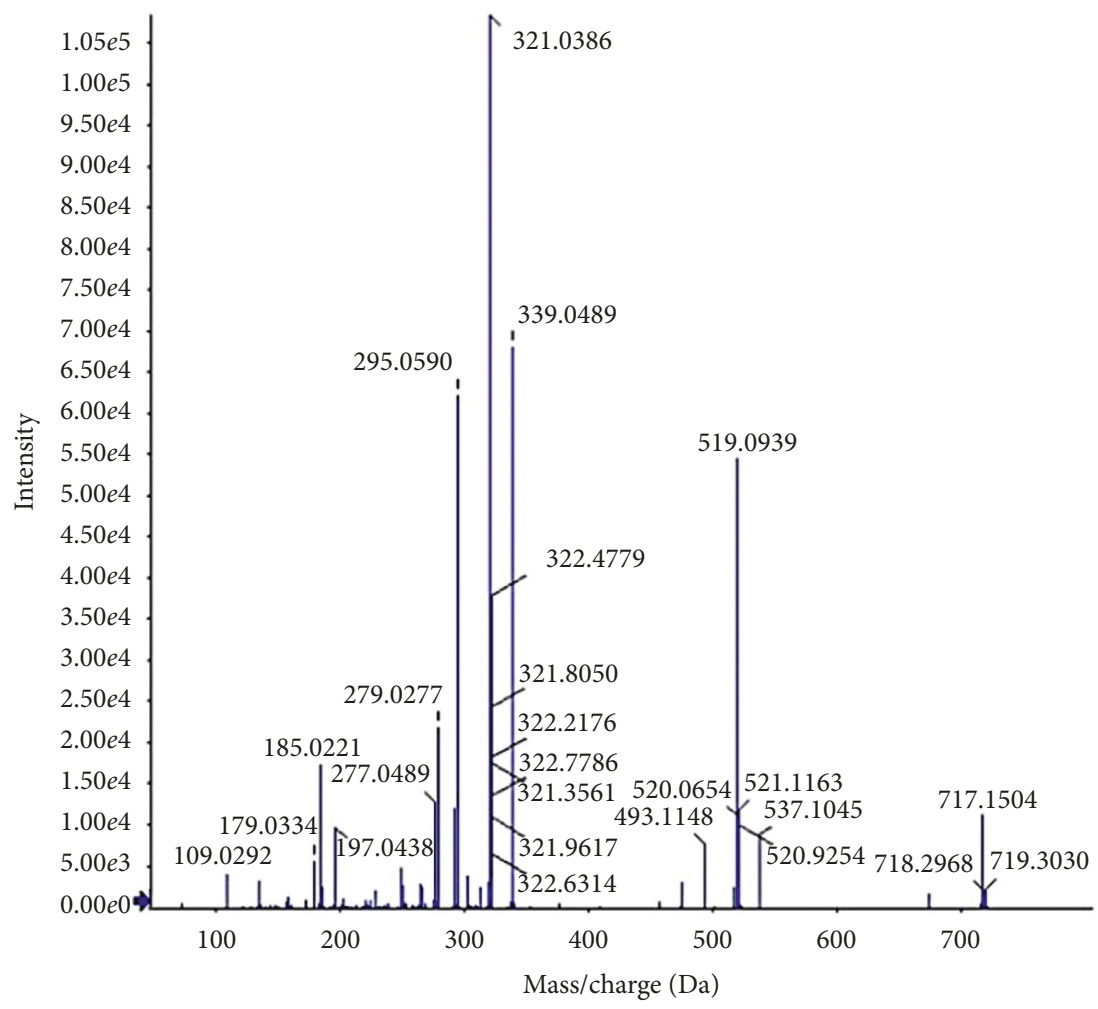

(e)

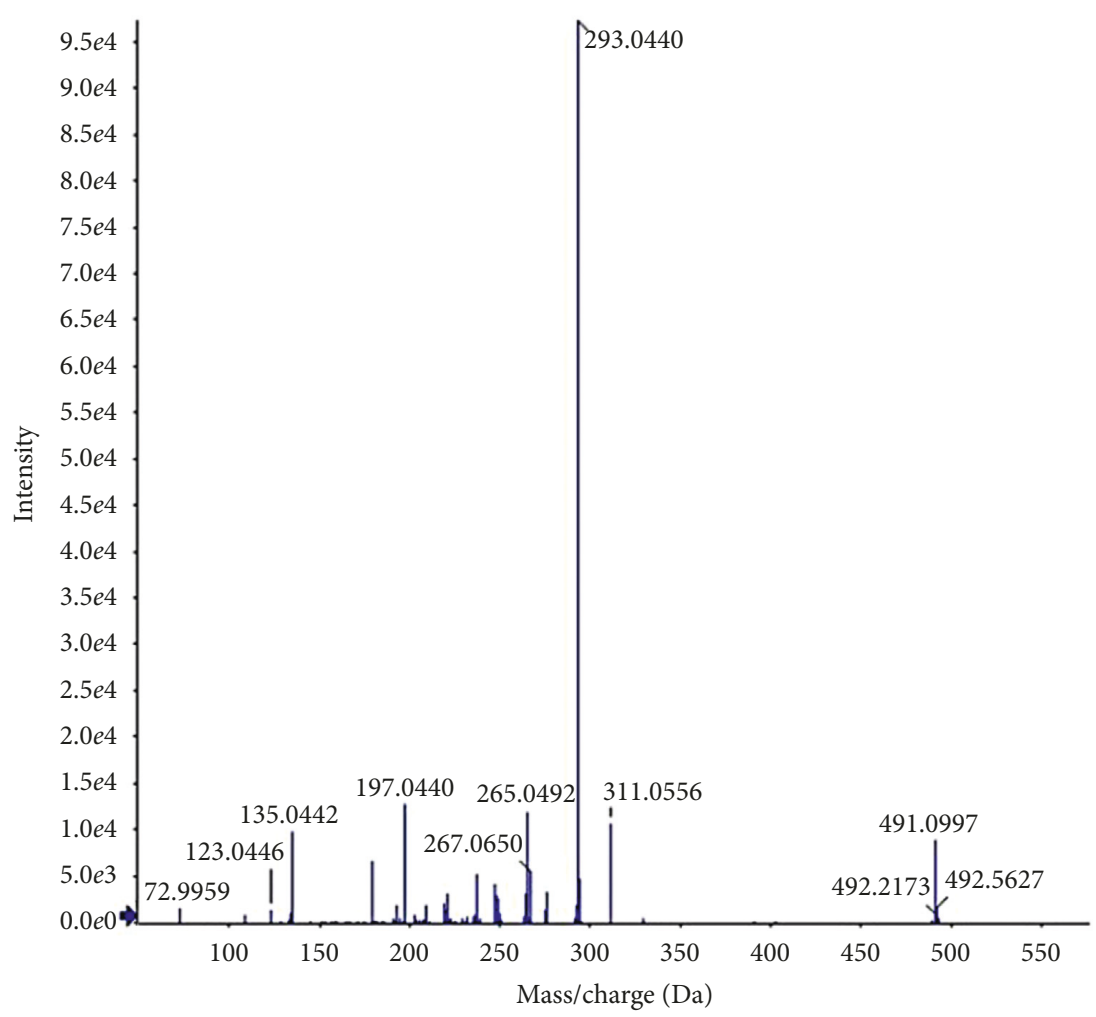

(f)

Figure 2: MS ${ }^{2}$ spectra of peak 2 (a), peak 11 (b), peak 16 (c), peak 22 (d), peak 23 (e), and peak 26 (f) in the QHYRF. 
<smiles>O=C(O)CCc1ccc(O)c(O)c1</smiles>

(a)<smiles>O=C(O)OC(Cc1ccc(O)c(O)c1)C(=O)O</smiles>

(d)

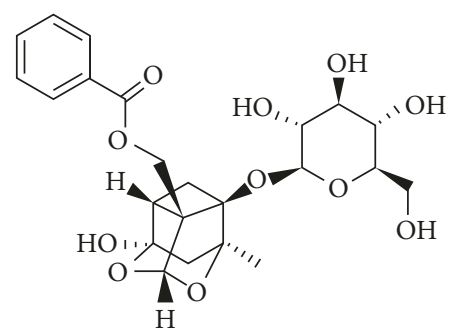

(b)<smiles>O=C(/C=C/c1ccc(O)c2c1[C@@H](C(=O)OC(Cc1ccc(O)c(O)c1)C(=O)O)C(c1ccc(O)c(O)c1)O2)OC(Cc1ccc(O)c(O)c1)C(=O)O</smiles>

(e)<smiles>C[C@@H]1C[C@H](CC2C(OC(=O)/C=C/c3ccc(O)c(O)c3)[C@H](CO)CC(OCCc3ccc(O)c(O)c3)[C@@H]2O)[C@H](O)[C@H](O)[C@H]1O</smiles>

(c)<smiles>O=C(/C=C/c1ccc(O)c2c1CC(c1ccc(O)c(O)c1)O2)O[C@@H](Cc1ccc(O)c(O)c1)C(=O)O</smiles>

(f)

Figure 3: Chemical structure of danshensu (a), paeoniflorin (b), acteoside (c), lithospermic acid (d), salvianolic acid B (e), and salvianolic acid C (f).

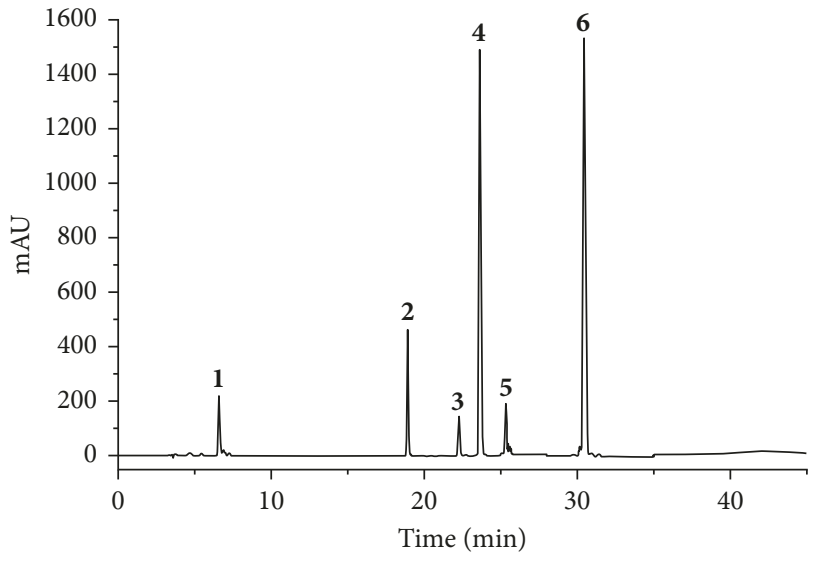

FIgURE 4: HPLC chromatogram of QHYRF using UV detector. Danshensu (1), paeoniflorin (2), acteoside (3), lithospermic acid (4), salvianolic acid B (5), and salvianolic acid C (6).

two compounds yielded similar product ions at $m / z 193$ and 134. Compared with literatures [16, 17], compounds 5 and $\mathbf{1 0}$ were tentatively assigned as 5-O-feruloylquinic acid and 3O-feruloylquinic acid, respectively.

Monoterpene glycosides exhibited quasi-molecular ions $[\mathrm{M}-\mathrm{H}]^{-}$and $[\mathrm{M}-\mathrm{H}+\mathrm{HCOO}]^{-}$in the negative ion mode. The chemical structure of aglycones is a "cage-like" pinane skeleton, which is very unusual among natural products. The monoterpene glycosides in QHYRF were usually esterified with an aromatic acid such as benzoic acid, vanillic acid, methoxybenzoic acid, and gallic acid. A total of nine monoterpene glycosides were identified. Peaks 4, 11, and 15 displayed the same $[\mathrm{M}-\mathrm{H}]^{-}$ion at $\mathrm{m} / z 525$ with the molecular composition $\mathrm{C}_{24} \mathrm{H}_{30} \mathrm{O}_{13}$. Peaks $\mathbf{1 1}$ and $\mathbf{1 5}$ produced the same product ions at $\mathrm{m} / z 479,449$, and 121 . In comparison with the standard, peak 11 was unambiguously identified as paeoniflorin (Figure 2(b)). Peak 15 was plausibly assigned as the paeoniflorin isomer. Peak $\mathbf{4}$ yielded the product ions at $m / z 495$ and 167. In comparison with the literature [18], peak 4 was deduced as mudanpioside E. Peak 3 gave the $[\mathrm{M}-\mathrm{H}]^{-}$ions at $m / z 495.1498\left(\mathrm{C}_{23} \mathrm{H}_{28} \mathrm{O}_{12}\right)$ and was $16 \mathrm{Da}(\mathrm{O})$ more than that of paeoniflorin. It produced fragment ions at $m / z 465.1437$ ([M-H-HCOH $\left.]^{-}\right)$, indicating that peak 3 may be oxypaeoniflorin based on a previously reported literature data [13]. Peaks 6 and 7 displayed the same $[\mathrm{M}-\mathrm{H}]^{-}$ions at $\mathrm{m} / z 505.1562\left(\mathrm{C}_{20} \mathrm{H}_{28} \mathrm{O}_{12}\right)$ and generated similar product ions at $m / z$ 459, 293, and 150 . Compared with literatures [19], peaks 6 and 7 were tentatively deduced as paeonolide and apiopaeonoside, respectively. Peak 8 revealed the $[\mathrm{M}-\mathrm{H}]^{-}$ion at $m / z$ 647.1615, which was $152 \mathrm{Da}$ (galloyl group, $\mathrm{C}_{7} \mathrm{H}_{4} \mathrm{O}_{4}$ ) more than that of peak 3. This produced fragment ions at $m / z 629,509$, and 491 by a series of losses of one $\mathrm{H}_{2} \mathrm{O}$ molecule, one benzoic acid molecule, and one $\mathrm{H}_{2} \mathrm{O}$ molecule, respectively. Compared with the literature [20], peak 8 was tentatively characterized as 6-O-galloyloxypaeoniflorin. Peak 25 gave the $[\mathrm{M}-\mathrm{H}]^{-}$ions at $\mathrm{m} / z 599.1769\left(\mathrm{C}_{30} \mathrm{H}_{32} \mathrm{O}_{13}\right)$ and was 104 Da more than that of peak 3 . This produced fragment ions at $m / z 569$ and 477, indicating that peak 25 may be benzoyloxypaeoniflorin, based on a previously reported literature data [19]. Peak 27 revealed the $[\mathrm{M}-\mathrm{H}]^{-}$ions at $m / z 629.1872$ 
TABLE 2: Linear regression data, LODs, and LOQs of six compounds.

\begin{tabular}{lccccc}
\hline Components & Regression equations & $R^{2}$ & Linear range $(\mu \mathrm{g} / \mathrm{mL})$ & LODs $(\mu \mathrm{g} / \mathrm{mL})$ & LOQs $(\mu \mathrm{g} / \mathrm{mL})$ \\
\hline Danshensu & $y=5508.1 x+5.404$ & 0.9999 & $2.6-500$ & 0.7 & 5.0 \\
Paeoniflorin & $y=419.45 x-6.7219$ & 0.9994 & $20.8-25,000$ & 1.0 & 2.6 .8 \\
Acteoside & $y=3283.3 x-11.072$ & 0.9997 & $5.2-1000$ & 0.6 & 5.2 \\
Lithospermic acid & $y=12900 x-123.54$ & 0.9991 & $10.4-1000$ & $5.2-10,000$ & 10.4 \\
Salvianolic acid B & $y=1616.6 x-9.4854$ & 0.9993 & $10.4-1000$ & 0.8 & 10.4 \\
Salvianolic acid C & $y=19071 x+88.12$ & 1.0000 & & \\
\hline
\end{tabular}

$y=A x+B ; y$ is the peak area; $x$ is the concentration of the analytes; $R^{2}$ is the correlation coefficient of the equation.

Table 3: Precision and stability of six compounds in QHYRF $(n=6)$.

\begin{tabular}{lccc}
\hline Components & & Precision & \\
& Intraday RSD (\%) & Interday RSD (\%) & Stability RSD (\%) \\
\hline Danshensu & 3.8 & 2.2 & 4.7 \\
Paeoniflorin & 1.6 & 1.7 & 4.2 \\
Acteoside & 4.3 & 1.2 & 2.8 \\
Lithospermic acid & 4.1 & 1.6 & 2.8 \\
Salvianolic acid B & 4.8 & 1.2 & 2.4 \\
Salvianolic acid C & 4.7 & 1.2 & 3.9 \\
\hline
\end{tabular}

and was $104 \mathrm{Da}$ more than that of paeoniflorin. Compared with the literature [16], peak 27 was tentatively characterized as benzoylpaeoniflorin.

Iridoids were also observed in the formula. Peaks 16 and 17 revealed the same $[\mathrm{M}-\mathrm{H}]^{-}$at $m / z 623$ and produced the same fragments at $m / z 461$ and 161 . Compared with the standard, compound $\mathbf{1 6}$ was unambiguously identified as acteoside (Figure 2(c)). The retention time of peak $\mathbf{1 7}$ was a little later than that of peak 16. Compared with the literature, compound $\mathbf{1 7}$ was tentatively deduced as forsythoside A. Peak 9 displayed the $[\mathrm{M}-\mathrm{H}]^{-}$ion at $\mathrm{m} / \mathrm{z}$ 785.2520 with the molecular composition $\mathrm{C}_{35} \mathrm{H}_{46} \mathrm{O}_{20}$. This produced product ions at $\mathrm{m} / z 623$ [M-Glc] $^{-}, 477$ [M-GlcAra $]^{-}$, and 179. In comparison with the literature, compound $\mathbf{9}$ was tentatively deduced as echinacoside. Peaks $\mathbf{1 2}$ and 13 revealed the same $[\mathrm{M}-\mathrm{H}]^{-}$ions at $m / z 611.1621$ and yielded product ions at $\mathrm{m} / z 445$ and 169 . Compared with the reference [21], compounds $\mathbf{1 2}$ and $\mathbf{1 3}$ were tentatively characterized as hydroxysafflor yellow A and its isomer.

\subsection{Development and Validation of the HPLC-UV Approach.} The HPLC separation conditions were optimized including the mobile phase system, column temperature, and UV detection wavelength. In order to obtain chromatograms with better resolution of the adjacent peaks and shorter time, methanol and acetonitrile were compared in the experiment. The result indicated that acetonitrile was better than methanol due to shorter analysis time and better peak shape. In addition, the different column temperatures were also optimized. Finally, $30^{\circ} \mathrm{C}$ was chosen as the best column temperature. Under present HPLC conditions, the samples of QHYRF and standard solutions were analyzed. The UV absorption and detection wavelength of each compound were confirmed as follows: paeoniflorin, lithospermic acid and salvianolic acid B $(254 \mathrm{~nm})$, danshensu and salvianolic acid C $(280 \mathrm{~nm})$, and acteoside $(320 \mathrm{~nm})$ (chemical structure is shown in Figure 3).

According to the representative chromatograms of the standard solution, sample solution, and negative control samples solution, it could be found that the determination of these six compounds does not interfere with each other (Figure 4).

The calibration curves of danshensu, paeoniflorin, acteoside, lithospermic acid, salvianolic acid B, and salvianolic acid $C$ were linear within the range of 2.6-500, 20.8-25,000, $5.2-1000,10.4-1000,5.2-10,000$, and $10.4-1000 \mu \mathrm{g} / \mathrm{mL}$, respectively. The correlation coefficient $\left(R^{2}\right)$ of all six standards revealed a good linearity of $>0.991$ in the aforementioned ranges. The LODs and LOQs of these six compounds were $0.6-5.0$ and $2.6-20.8 \mu \mathrm{g} / \mathrm{mL}$, respectively (Table 2).

Intraday and interday variations were chosen to evaluate the precision of the method. These results are shown in Table 2. It was revealed that the intraday and interday RSDs were within the range of $1.6 \%-4.8 \%$ and $1.2 \%-2.2 \%(n=6)$. The stability of six major compounds ranged from $2.8 \%$ to $4.7 \%$, which met the requirements of the analytical approach (Table 3).

The recovery data are shown in Table 4, which represents the accuracy of the method and was sufficient for the analysis. The measured data indicated that the recovery of these six components ranged from $99.0 \%$ to $104.7 \%$.

3.3. Application. The established HPLC-UV approach was employed for simultaneously quantifying the six active components in 10 batches of QHYRF. These results are presented in Table 5. Furthermore, these results revealed that there were small differences among the contents of the six major constituents in different batches of QHYRF.

Optimized chromatographic conditions for the good resolution of adjacent peaks were achieved after several trials with elution systems of acetonitrile-water, methanol-water, acetonitrile-acid, and methanol-acid in different proportions. 
TABLE 4: Recovery of six compounds in QHYRF $(n=3)$.

\begin{tabular}{|c|c|c|c|c|c|c|}
\hline Components & $\begin{array}{l}\text { Contents } \\
(\mathrm{mg} / \mathrm{mL})\end{array}$ & $\begin{array}{l}\text { Quantity added } \\
(\mathrm{mg} / \mathrm{mL})\end{array}$ & $\begin{array}{c}\text { Theoretical amount } \\
(\mathrm{mg} / \mathrm{mL})\end{array}$ & $\begin{array}{c}\text { Recorded amount } \\
(\mathrm{mg} / \mathrm{mL})\end{array}$ & $\begin{array}{c}\text { Recovery } \\
(\%)\end{array}$ & $\begin{array}{l}\text { RSD } \\
(\%)\end{array}$ \\
\hline \multirow{3}{*}{ Danshensu } & \multirow{3}{*}{0.22} & 0.05 & 0.27 & 0.27 & 100.6 & 1.7 \\
\hline & & 0.11 & 0.33 & 0.33 & 100.0 & 3.3 \\
\hline & & 0.2 & 0.42 & 0.42 & 100.2 & 1.8 \\
\hline \multirow{3}{*}{ Paeoniflorin } & \multirow{3}{*}{12.32} & 2.45 & 14.77 & 14.78 & 100.4 & 0.4 \\
\hline & & 4.95 & 17.27 & 17.27 & 100.0 & 2 \\
\hline & & 7.85 & 20.17 & 20.17 & 100.0 & 5.4 \\
\hline \multirow{3}{*}{ Acteoside } & \multirow{3}{*}{0.07} & 0.15 & 0.22 & 0.22 & 103.1 & 3.7 \\
\hline & & 0.22 & 0.29 & 0.29 & 99.0 & 5.5 \\
\hline & & 0.42 & 0.49 & 0.49 & 100.6 & 5.3 \\
\hline \multirow{3}{*}{ Lithospermic acid } & \multirow{3}{*}{0.1} & 0.08 & 0.18 & 0.18 & 102.6 & 4.3 \\
\hline & & 0.15 & 0.25 & 0.25 & 103.3 & 5.4 \\
\hline & & 0.27 & 0.37 & 0.38 & 102.2 & 1.7 \\
\hline \multirow{3}{*}{ Salvianolic acid B } & \multirow{3}{*}{4.96} & 1 & 5.96 & 5.96 & 99.9 & 3.7 \\
\hline & & 2.23 & 7.19 & 7.19 & 100.0 & 3.5 \\
\hline & & 3.41 & 8.37 & 8.37 & 100.1 & 2.2 \\
\hline \multirow{3}{*}{ Salvianolic acid C } & \multirow{3}{*}{0.01} & 0.09 & 0.1 & 0.10 & 103.6 & 3 \\
\hline & & 0.21 & 0.22 & 0.22 & 99.0 & 2.3 \\
\hline & & 0.35 & 0.36 & 0.38 & 104.7 & 4.8 \\
\hline
\end{tabular}

TABle 5: Content of six components in 10 batches of the QHYRF.

\begin{tabular}{|c|c|c|c|c|c|c|c|c|c|c|}
\hline \multirow{2}{*}{ Components } & \multicolumn{10}{|c|}{ Content $(\mathrm{mg} / \mathrm{g})$} \\
\hline & 1 & 2 & 3 & 4 & 5 & 6 & 7 & 8 & 9 & 10 \\
\hline Danshensu & 9.8 & 10.0 & 9.8 & 10.0 & 10.0 & 9.8 & 10.1 & 10.2 & 10.0 & 9.7 \\
\hline Paeoniflorin & 582.6 & 591.2 & 612.4 & 579.8 & 617.3 & 591.4 & 609.3 & 582.4 & 582.0 & 601.4 \\
\hline Acteoside & 3.4 & 3.4 & 3.3 & 3.4 & 3.3 & 3.3 & 3.5 & 3.2 & 3.4 & 3.4 \\
\hline Lithospermic acid & 4.5 & 4.7 & 4.6 & 4.4 & 4.5 & 4.6 & 4.6 & 4.5 & 4.6 & 4.6 \\
\hline Salvianolic acid B & 265.9 & 266.4 & 260.5 & 260.7 & 263.4 & 262.6 & 272.8 & 263.5 & 264.8 & 270.7 \\
\hline Salvianolic acid C & 0.5 & 0.5 & 0.5 & 0.5 & 0.5 & 0.5 & 0.5 & 0.5 & 0.5 & 0.5 \\
\hline
\end{tabular}

It was found that the presence of $0.1 \%$ fomic acid resulted in the significant improvement on the retention behavior of the different components. The optimal mobile phase, which consists of acetonitrile- $0.1 \%$ fomic acid, was finally employed. This led to its high resolution and symmetrical peak shape.

According to the theory of TCM, QHYRF was prepared by six herbal medicines to cure the disease of diabetic cardiomyopathy. The presence of the researched active compounds in QHYRF was proved, making it possible to suggest a therapeutic effect in clinical applications. However, it enhances the complexity of the constituents and preparation procedures, which make it difficult to ensure the batch-to-batch uniformity of QHYRF. Thus, the quantitative measurement of its bioactive components is extremely necessary during the preparation and application of this prescription.

In recent years, methods for multicomponent analysis have become a credible solution for the analysis of a complex system in TCM. At present, we developed a sensitive HPLC-UV method to simultaneously quantify six active components in 10 different batches of QHYRF. A slight variation was observed in the different batches of QHYRF during the determination of the six major constituents, which reveal that the present preparation of QHYRF has good reproducibility. Furthermore, good reproducibility ensures the safety and effects of QHYRF in clinical application.

\section{Conclusion}

In summary, a simple and sensitive UHPLC-Q-TOF/MS method was established to qualitatively analyze the chemical components of QHYRF. Twenty-seven compounds were identified or tentatively characterized based on retention time, and $\mathrm{MS}^{1}$ and $\mathrm{MS}^{2}$ data, or by comparing with standards and literatures. These compounds include 12 phenolic acids, nine monoterpene glycosides, two flavonoids, three iridoids, and one unknown compound. A HPLC-UV method for the simultaneous determination of six active components from QHYRF was developed and well validated, showing its excellent precision, stability, and recovery. In addition, these results indicate a slight variation in the contents of the six major constituents among the different batches of QHYRF. This is the first comprehensive study that qualitatively and quantitatively determined the chemical constituents of QHYRF using UHPLC-QTOF/MS and HPLC-UV. Thus, these findings could serve as a foundation for the quality control or further research of QHYRF. 


\section{Conflicts of Interest}

The authors declare that they have no conflicts of interest regarding the publication of this study.

\section{Authors' Contributions}

Xin Shao and Jie Zhao contributed equally to this work.

\section{Acknowledgments}

This study was financially supported by the Natural Science Foundation of Jiangsu Province (no. BK20151572), the Natural Science Foundation for the Youth of Jiangsu Province (no. BK20140963), the Nutritional Science Foundation of By-Health Co. (no. TY0141103), and the Priority Academic Program Development of Jiangsu Higher Education Institution (PAPD).

\section{References}

[1] J. R. Sowers, M. Epstein, and E. D. Frohlich, "Diabetes, hypertension, and cardiovascular disease: an update," Hypertension, vol. 37, no. 4, pp. 1053-1059, 2001.

[2] S. Rubler, J. Dlugash, Y. Z. Yuceoglu, T. Kumral, A. W. Branwood, and A. Grishman, "New type of cardiomyopathy associated with diabetic glomerulosclerosis," American Journal of Cardiology, vol. 30, no. 6, pp. 595-602, 1972.

[3] A. G. Bertoni, W. G. Hundley, M. W. Massing, D. E. Bonds, G. L. Burke, and D. C. Goff Jr., "Heart failure prevalence, incidence, and mortality in the elderly with diabetes," Diabetes Care, vol. 27, no. 3, pp. 699-703, 2004.

[4] X. Zhou, S. W. Chan, H. L. Tseng et al., "Danshensu is the major maker for the antioxidant and vasorelaxation effects of Danshen (Salvia miltiorrhiza) water-extracts produced by different heat water-extractions," Phytomedicine, vol. 19, no. 14, pp. 1263-1269, 2012.

[5] Y. Sun, J. Zhang, R. Huo et al., "Paeoniflorin inhibits skin lesions in imiquimod-induced psoriasis-like mice by downregulating inflammation," International Immunopharmacology, vol. 24, no. 2, pp. 392-399, 2015.

[6] K. K. Au-Yeung, D. Y. Zhu, O. Karmin, and Y. L. Siow, "Inhibition of stress-activated protein kinase in the ischemic used heart: role of magnesium tanshinoate B in preventing apoptosis," Biochemical Pharmacology, vol. 62, no. 4, pp. 483-493, 2001.

[7] Y. Ren, S. Tao, S. Zheng et al., "Salvianolic acid B improves vascular endothelial function in diabetic rats with blood glucose fluctuations via supression of endothelial cell apoptosis," European Journal of Pharmacology, vol. 791, pp. 308-315, 2016.

[8] H. Bing, Effects of Qing-Hua-Yu-Re Formula on Diabetic Cardiomyopathy in Rats and Possible Mechanisms, Ph.D. thesis, Nanjing University of Chinese Medicine Department, Nanjing, China, 2010.

[9] W. Xu, B. Hong, Z. XuePing, S. Xin, and Z. Li, "Clinical research of Qing-Hua-Yu-Re formula in treating diabetic cardiomyopathy," Journal of Nanjing University of Traditional Chinese Medicine, vol. 26, pp. 412-414, 2010.

[10] K. An, G. Jin-Rui, Z. Zhen, and W. Xiao-Long, "Simultaneous quantification of ten active components in traditional Chinese formula sijunzi decoction using a UPLC-PDA method," Journal of Analytical Methods in Chemistry, vol. 2014, Article ID 570359, 8 pages, 2014.
[11] K. Zhong, "Current analysis of the factors affecting the efficacy of traditional Chinese medicine," Journal of North Pharmacy, vol. 8, pp. 67-68, 2011.

[12] Y. Tao, Y. Jiang, W. Li, and B. Cai, "Rapid characterization and determination of isoflavones and triterpenoid saponins in $\mathrm{Fu}-$ Zhu-Jiang-Tang tablets using UHPLC-Q-TOF/MS and HPLCUV," Analytical Methods, vol. 8, no. 21, pp. 4211-4219, 2016.

[13] H. Chen, Q. Zhang, X. Wang, J. Yang, and Q. Wang, "Qualitative analysis and simultaneous quantification of phenolic compounds in the aerial parts of Salvia miltiorrhiza by HPLC-DAD and ESI/MS(n)," Phytochemical Analysis, vol. 22, no. 3, pp. 247-257, 2011.

[14] M. Liu, S. Zhao, Y. Wang et al., "Identification of multiple constituents in Chinese medicinal prescription Shensong Yangxin capsule by ultra-fast liquid chromatography combined with quadrupole time-of-flight mass spectrometry," Journal of Chromatographic Science, vol. 53, no. 2, pp. 240252, 2015.

[15] X. Li, F. Du, W. Jia et al., "Simultaneous determination of eight Danshen polyphenols in rat plasma and its application to a comparative pharmacokinetic study of DanHong injection and Danshen injection," Journal of Separation Science, vol. 40, no. 7, pp. 1470-1481, 2017.

[16] D. Gao, B. Wang, Z. Huo et al., "Analysis of chemical constituents in an herbal formula Jitong Ning tablet," Journal of Pharmaceutical and Biomedical Analysis, vol. 140, pp. 301312, 2017.

[17] Y. Zhao, M. X. Chen, K. T. Kongstad, A. K. Jäger, and D. Staerk, "Potential of polygonum cuspidatum root as an antidiabetic food: dual high-resolution $\alpha$-glucosidase and PTP1B inhibition profiling combined with HPLC-HRMS and NMR for identification of antidiabetic constituents," Journal of Agricultural and Food Chemistry, vol. 65, no. 22, pp. 44214427, 2017.

[18] Y.-H. Shi, S. Zhu, Y.-W. Ge et al., "Characterization and quantification of monoterpenoids in different types of peony root and the related Paeonia species by liquid chromatography coupled with ion trap and time-of-flight mass spectrometry," Journal of Pharmaceutical and Biomedical Analysis, vol. 129, pp. 581-592, 2016.

[19] P. Li, W. Su, C. Xie, X. Zeng, W. Peng, and M. Liu, "Rapid identification and simultaneous quantification of multiple constituents in Nao-Shuan-Tong capsule by ultra-fast liquid chromatography/diode-array detector/quadrupole time-of-flight tandem mass spectrometry," Journal of Chromatographic Science, vol. 53, no. 6, pp. 886-897, 2015.

[20] Q. Wang, Z. Liang, Y. Peng et al., "Whole transverse section and specific-tissue analysis of secondary metabolites in seven different grades of root of Paeonia lactiflora using laser microdissection and liquid chromatography-quadrupole/time of flight-mass spectrometry," Journal of Pharmaceutical and Biomedical Analysis, vol. 103, pp. 7-16, 2015.

[21] L. Zuo, Z. Sun, Y. Hu et al., "Rapid determination of 30 bioactive constituents in XueBijing injection using ultra high performance liquid chromatography-high resolution hybrid quadrupole-orbitrap mass spectrometry coupled with principal component analysis," Journal of Pharmaceutical and Biomedical Analysis, vol. 137, pp. 220-228, 2017. 

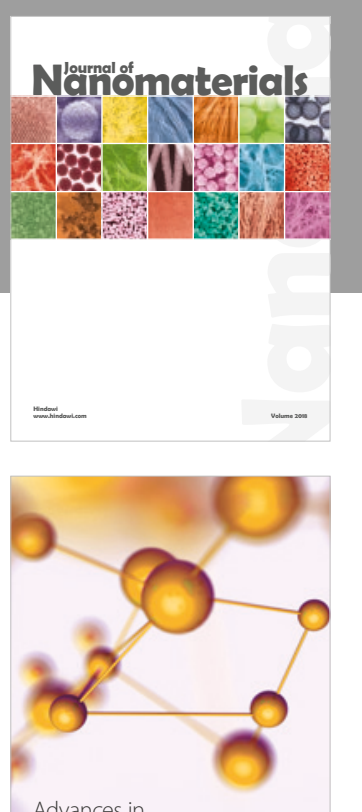

Physical Chemistry
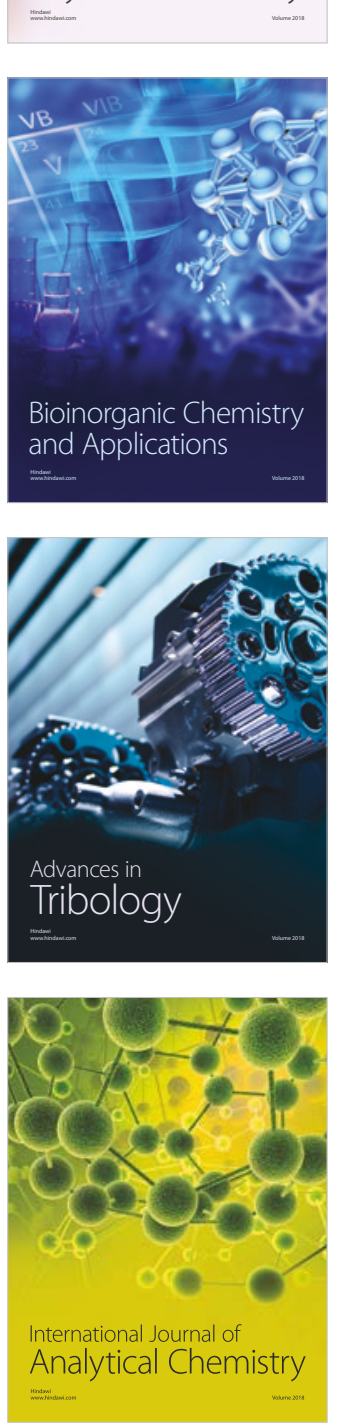

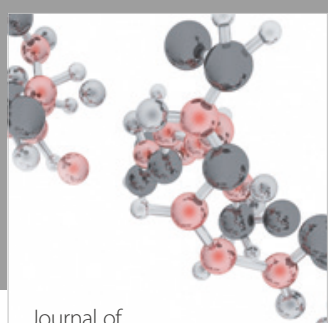

Analytical Methods

in Chemistry

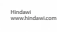

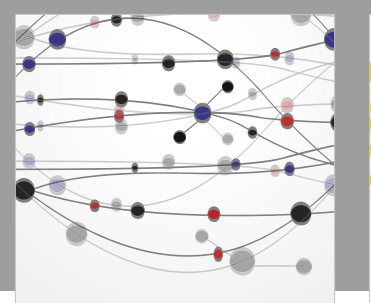

The Scientific World Journal

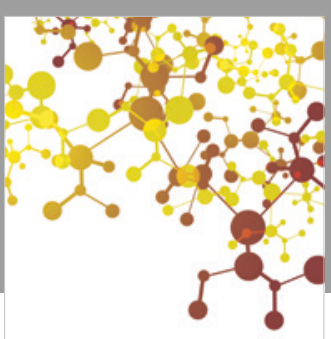

Journal of

Applied Chemistry
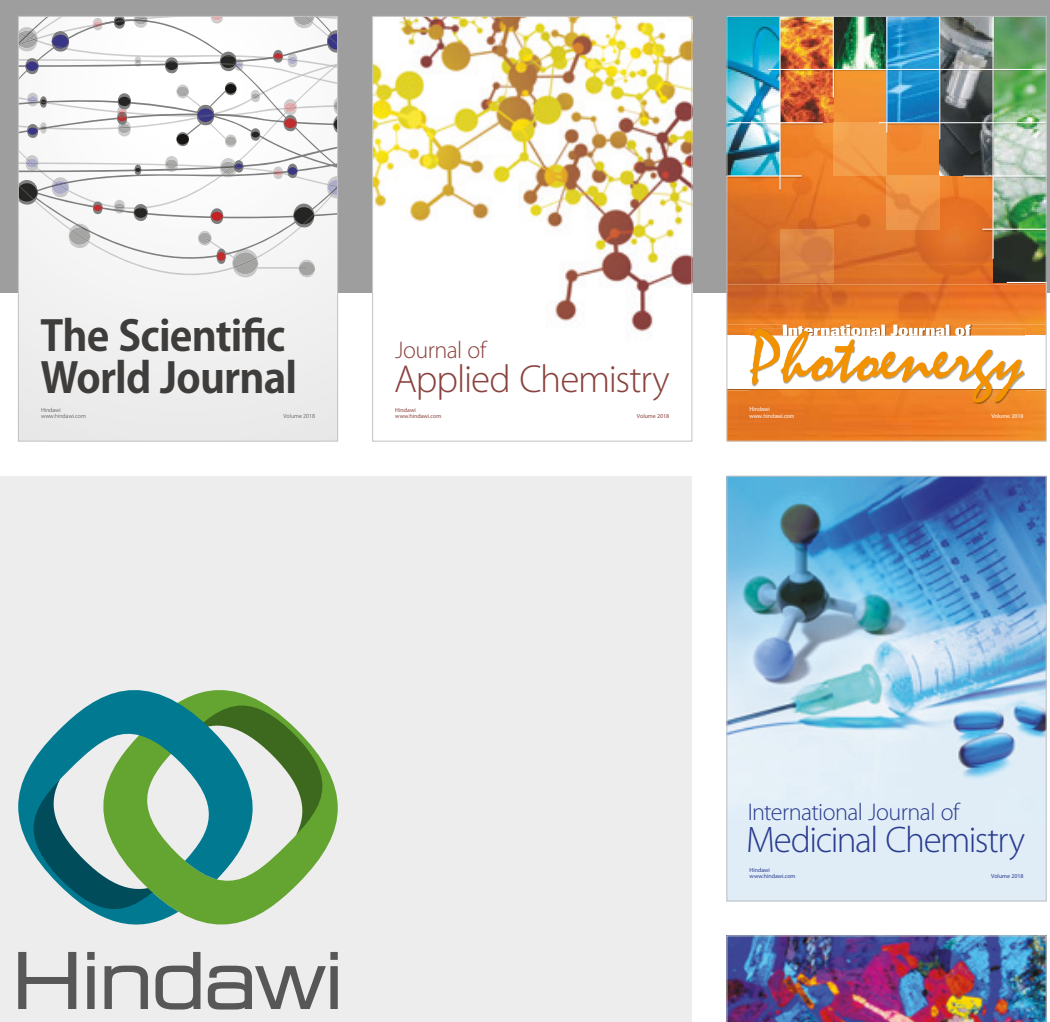

Submit your manuscripts at

www.hindawi.com
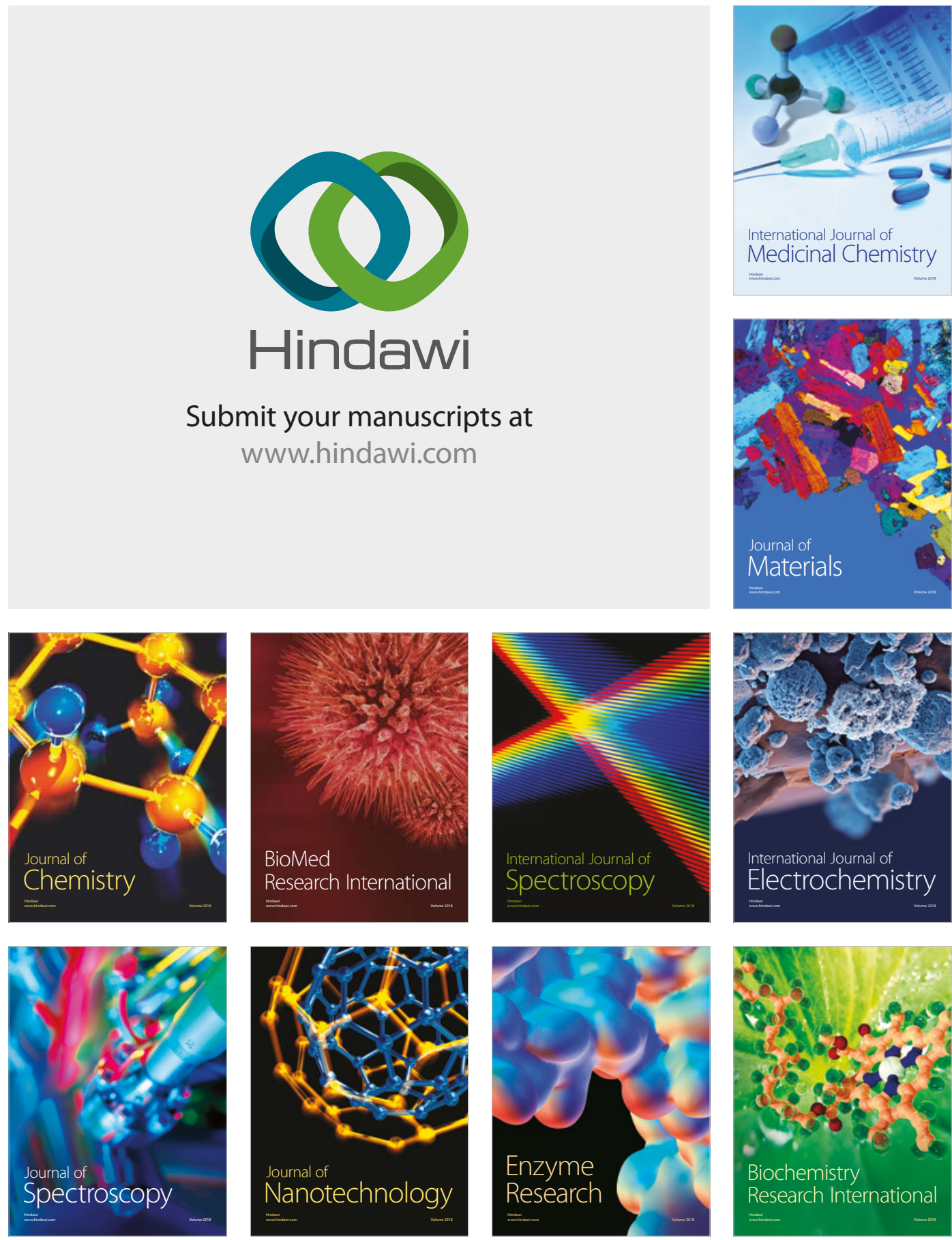
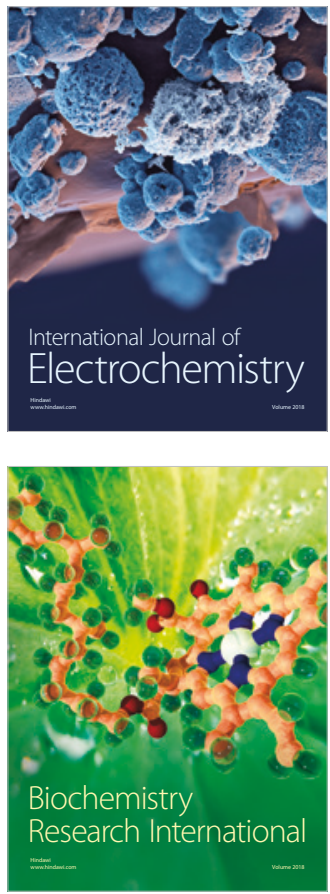